\title{
Optimization of Tandem Affinity Chromatography (TAP) for Effective Isolation and Identification of Protein Complexes Involved in Molecular Mechanism of Depression.
}

\section{Ewelina Fic ( $\nabla$ ewelina.fic@uj.edu.pl)}

Department of Physical Biochemistry, Faculty of Biochemistry, Biophysics and Biotechnology, Jagiellonian University https://orcid.org/0000-0001-8353-5753

\section{Agata Cieslik}

Department of Physical Biochemistry, Faculty of Biochemistry, Biophysics and Biotechnology, Jagiellonian University: Uniwersytet Jagiellonski w Krakowie

\section{Marta Dziedzicka-Wasylewska}

Department of Physical Biochemistry, Faculty of Biochemistry, Biophysics and Biotechnology, Jagiellonian University: Uniwersytet Jagiellonski w Krakowie

\section{Short Report}

Keywords: Depression, Affinity tags, Interactomics, PC12 cell line

Posted Date: February 4th, 2021

DOl: https://doi.org/10.21203/rs.3.rs-179346/v1

License: (c) (i) This work is licensed under a Creative Commons Attribution 4.0 International License. Read Full License 


\section{Abstract}

According to the World Health Organization Report, depressive disorders affect about $10 \%$ of the population. The molecular mechanism of the pathogenesis of depression is still not well understood. The new findings point to phosphatases as potential targets for effective depression therapy. The aim of the project is the development of method that would enable the identification of Mitogen-Activated Protein Kinase Phosphatase-1 (MKP-1) protein partners using proteomic techniques. The research was carried out using the PC12 cell line, often used as a model for neurobiological research. The use of the procedure for efficient purification of protein complexes - Tandem Affinity Purification (TAP) will facilitate the identification of proteins interacting with MKP-1, a potential goal of effective antidepressant therapy. The presented protocol for purification of protein complexes is universal and can be successfully used in different mammalian cell lines. Identified proteins belong to various groups: cytoskeletal, ribosomal, nucleic acid binding, chaperones, enzymes and may potentially be involved in the molecular mechanism of depression.

\section{Introduction}

The depression is a severe mental disorder characterized by depressed mood, cognitive and executive impairment. The molecular mechanisms underlying this illness or the effects of antidepressants are still unknown. It seems that advanced biochemical studies may contribute to a better understanding of the etiopathogenesis of depression. It is estimated that about $80 \%$ of proteins perform their functions in complexes with other proteins. These protein-protein interactions (Protein-Protein Interactions - PPIs) are examined by interactomics. The purification strategy of protein complexes, defined as Tandem Affinity Purification, TAP, in combination with mass spectrometry, allows the purification of native protein complexes and identification of interacting partners [1]. TAP is a strategy that allows the isolation of protein complexes from various tissues. This method is based on the use of 2-3 different tags attached to the tested protein and the introduction of the construct into host cells [2]. Thanks to the combination of tags from the proteins mixture, "native" complexes of a given protein with other proteins, using the affinity chromatography method, are extracted [3].

The literature reports have suggested the important role of Mitogen-Activated Protein Kinase Phosphatase-1 (MKP-1) in the pathogenesis of depression and other neuropsychiatric disorders $[4,5]$. MKP-1 belongs to a family of proteins that dephosphorylate serine/threonine and tyrosine amino acid residues [6]. The MKP-1 protein was identified as a negative regulator of the MAPK (Mitogen-Activated Protein Kinase) cascade [4], which is associated with the occurrence of depressive symptoms. Experiments carried out using the animal model of depression show that the increase in mkp-1 gene expression in the hippocampus leads to the occurrence of depressive symptoms. Chronic treatment with antidepressants normalizes symptoms caused by excess MKP-1, and mice lacking the mkp-1 gene are resistant to stress. Post-mortem studies on the brains of people diagnosed with depression also showed an elevated level of MKP-1 expression and associated with ERK (Extracellular Signal-Regulated Kinases) signal inhibition. Administration of sanguinarine, a selective MKP-1 inhibitor $[7,8]$ to the ventrolateral 
orbital cortex in rats significantly reduces depressive behavior in a dose-dependent manner compared to the control group. Decreased MKP-1 expression and increased ERK activation were also observed. MKP-1 inhibition may have antidepressant effects, as confirmed by behavioral tests with effects similar to those observed after fluoxetine treatment [9]. The results indicate that within the orbital cortex, MKP-1 is involved in the development of depression and may be a potential target for the pharmacotherapy of depression [8].

Recently published results indicate that other factors (not yet identified) may be critical for elevated MKP1 levels and thus result in depressive symptoms $[5,10]$.

The purpose of the presented study was the optimization of TAP strategy aimed at identifying MKP-1 protein partners. In the study the production of MKP-1 with Strep II FLAG -tag (SF-tag) was carried out on the cell line PC12 (rat adrenal pheochromocytoma cell line) - this line is a useful model for neurobiological and neurochemical research [11] and is successfully used in interactomic studies [12].

\section{Materials And Methods}

\subsection{Construct engineering}

The mkp-1 gene cloned into the pcDNA $3.1(+)$ vector with the FLAG tag attached to the C-terminus (tag composition: DYKDDDDK) was purchased at GenScript Biotech Corp. At the same time, primers were designed to enable the connection of the double Strep tag (composition of the tag: WSHPQFEK) in a several-step procedure, to the construct with the C-FLAG-tag. The primers were purchased at Genomed. The nucleotide sequences coding for the Strep-tagging amino acids were introduced using standard molecular biology techniques: QuikChange site-directed mutagenesis [13], restriction enzyme digestion, Escherichia coli cell transformation, isolation of plasmid DNA using commercial kits (Sigma-Aldrich). The correctness of joining the tags has been verified by sequencing the obtained constructs (Genomed).

\subsection{Cell culture and generation of cell lines stably expressing of MKP-1 with SF tag.}

PC12 cells purchased from American Type Culture Collection, were cultured in medium Ham's F-12K (Thermo Scientific), 15\% horse serum (Thermo Scientific), 5\% fetal bovine serum (Sigma-Aldrich), 1\% PenStrep (Sigma-Aldrich) at $37^{\circ} \mathrm{C}$ in humidity-saturated $5 \% \mathrm{CO}_{2}$ atmosphere. Once the cells have reached the appropriate confluence, they were transfected with reagent Escort III (Sigma-Aldrich), according to the manufacturer's protocol, to introduce a construct that allows the production of MKP-1 protein with an attached SF tag. G418 (Geneticin) antibiotic (Sigma-Aldrich) with a final concentration of $500 \mu \mathrm{g} / \mathrm{ml}$ was used as the selection agent. After 4 weeks of PC12 cell culture, several clones were selected in the presence of G418.

\subsection{Western blot}


The Western blot was carried out in accordance with the standard protocol (www.scbt.com/scbt/resources/protocols). Protein concentrations were determined using the Bradford assay [14]. The following four primary antibodies were used: mouse anti-FLAG M2, Clone M2 (Sigma Aldrich), mouse anti-DUT, mouse anti-fascin and mouse anti-drebrin (Santa Cruz Biotechnology).

Secondary antibody was mouse $\lg \mathrm{GK}_{\mathrm{K}}$ light chain binding protein ( $\left.\mathrm{m}-\lg \mathrm{GK} \mathrm{BP}\right)$ conjugated to horseradish peroxidase (Santa Cruz Biotechnology).

\subsection{SF-TAP Purification}

A stably transfected PC12 cells were cultured in order to obtain a sufficient number of cells $\left(\sim 5 \times 10^{8}\right.$ cells) to ensure efficient purification of protein complexes formed by the MKP-1 protein.

Cells were harvested and washed with PBS, resuspended in cell lysis buffer $(20 \mathrm{mM}$ Tris- $\mathrm{HCl} \mathrm{pH} \mathrm{7.5,} 150$ $\mathrm{mM} \mathrm{NaCl}, 1.5 \mathrm{mM} \mathrm{MgCl}_{2}, 1 \mathrm{mM}$ DTT, 5\% glycerol, 1\% (v/v) Nonidet P-40, Complete Mini Protease Inhibitor Cocktail (Roche). The suspension was vortexed and incubated at $4^{\circ} \mathrm{C}$ for $30 \mathrm{~min}$. on the rotator with $360^{\circ}$ rotation. After centrifuging for $10 \mathrm{~min} .\left(10000 \mathrm{x} \mathrm{g}, 4^{\circ} \mathrm{C}\right)$, the clear supernatants were added to StrepTactin Superflow (IBA Lifesciences) and incubated at $4^{\circ} \mathrm{C}$ for 3 hours on the rotator with $360^{\circ}$ rotation. After incubation the samples were centrifuged $\left(1500 \times \mathrm{g}, 2 \mathrm{~min}, 4^{\circ} \mathrm{C}\right)$. The beds were washed 4 times with wash buffer I (20 mM Tris-HCl pH 7.5, $250 \mathrm{mM} \mathrm{NaCl}, 1.5 \mathrm{mM} \mathrm{MgCl}_{2}, 1 \mathrm{mM} \mathrm{DTT}, 5 \%$ glycerol, $0.2 \%$ (v/v) Nonidet $\mathrm{P}-40)$, each incubating the beds for 5 minutes and centrifuging $\left(1500 \mathrm{x} \mathrm{g}, 2 \mathrm{~min}, 4^{\circ} \mathrm{C}\right)$. The next, resins were washed with wash buffer II (100 mM Tris-HCl pH 8.0, $150 \mathrm{mM} \mathrm{NaCl}, 1 \mathrm{mM}$ EDTA) and centrifuged $\left(1500 \mathrm{xg}, 2 \mathrm{~min}, 4^{\circ} \mathrm{C}\right)$. The STREP elution buffer (100 mM Tris-HCl pH 8.0, $150 \mathrm{mM} \mathrm{NaCl}, 1 \mathrm{mM}$ EDTA, 2.5 $\mathrm{mM}$ desthiobiotin) was added to the beds and incubated at $4^{\circ} \mathrm{C}$ for $30 \mathrm{~min}$ on a rotator with $360^{\circ}$ rotation. After this time, the resins were centrifuged $\left(1500 \times \mathrm{g}, 2 \mathrm{~min}, 4^{\circ} \mathrm{C}\right)$. The supernatant was transferred to antiFLAG-M2 affinity gel (Sigma-Aldrich) and incubated at $4^{\circ} \mathrm{C}$ overnight on a rotator with $360^{\circ}$ rotation. After overnight incubation, the resins were centrifuged $\left(1500 \times \mathrm{g}, 2 \mathrm{~min}, 4^{\circ} \mathrm{C}\right)$. The beds were then washed three times with wash buffer II, each incubating for $5 \mathrm{~min}$ and centrifuging $\left(1500 \times \mathrm{g}, 2 \mathrm{~min}, 4^{\circ} \mathrm{C}\right)$. The FLAG elution buffer ( $30 \mathrm{mM}$ Tris-HCl pH 7.4, $150 \mathrm{mM} \mathrm{NaCl}, 200 \mu \mathrm{g} / \mathrm{ml}$ FLAG peptide (Sigma-Aldrich)) was added to the beds and incubated at $4^{\circ} \mathrm{C}$ for 3 hours on the rotator with $360^{\circ}$ rotation to elute the bound proteins. After this time, the resins were centrifuged $\left(1500 \times \mathrm{g}, 2 \mathrm{~min}, 4^{\circ} \mathrm{C}\right)$.

The same procedure for isolating protein complexes was performed for untransfected PC12 cells that served as a negative control. After purification, SDS-PAGE [15] (4\% stacking gel, $12 \%$ separating gel) of obtained samples was combined with silver staining.

\subsection{Mass spectrometry analysis}

Spectrometric analysis was done in the Proteomics and Mass Spectrometry Laboratory at the Malopolska Center of Biotechology (Cracow, Poland). The eluates obtained from TAP procedure were prepared using the SP3 method based on the protocol [16], then the samples were prepared using the FASP method based on the protocol [17]. The measurements were made on a spectrometer with an Orbitrap type analyzer in combination with an LC system using the nanoESI ionization method (Thermo 
Scientific). The results obtained were analyzed and protein identification was carried out using the MASCOT package. The list of proteins identified by mass spectrometry was analyzed using the UniProt database (www.uniprot.org).

\section{Results And Discussion 3.1. Protein expression}

Sequencing of the constructs confirmed the generation of the MKP-1 protein cloned into the pcDNA 3.1 $(+)$ vector with the C-terminal SF-tag. Due to the presence of a catalytic domain with rhodanase activity near the N-terminus of the MKP-1 protein [6], a construct containing the SF-tag at the C-terminus of phosphatase was used to transfect cells. The tag at the N-terminus, despite its small size, could potentially disrupt the protein-protein interactions under study and lead to false identification results.

A stably transfected PC12 line was derived. It was decided to perform a stable transfection due to the fact that it allows obtaining a more uniform culture and physiological conditions, which reduced the risk of non-specific interactions in the experiments performed. Transient transfection is associated with high stress for cells, and therefore causes high expression of chaperone proteins, which could hinder the analysis of mass spectrometric results.

Western blot of selected clones from cell cultures (after transfection and G418 antibiotic selection) using the anit-FLAG antibody gave positive results (molecular weight of MKP-1 is equal to $39 \mathrm{kDa}$ ) (Fig. 1).

\subsection{Isolation and identification of MKP-1 interacting proteins}

Modifications to the TAP method have been successfully introduced into mammalian cell culture (PC12 cells), enabling efficient isolation of specifically interacting proteins. After silver staining, a band at around $40 \mathrm{kDa}$ was observed in samples, which corresponds to the size of the MKP-1 protein $-39 \mathrm{kDa}$ (Fig. 2). A band for MKP-1 protein is visible in the samples taken after elution from the anti-FLAG M2 agarose, which may indicate the high specificity of the tandem affinity chromatography method.

A comparative analysis of proteins present in positive transfected cultures and negative control was performed. When analyzing the results, only the proteins with the highest amount of peptides were taken into account, on the basis of which the given protein with high percentage coverage of the sequence was identified. The list of proteins identified by mass spectrometry was analyzed using the UniProt database. Based on the available information, the proteins are grouped according to their function. 35 proteins were identified in this way. The results are shown in Table 1. 
Table 1

Comparative analysis of proteins identified for PC12 cells transfected with the construct MKP-1 with SF tag versus negative control (untransfected PC12 cells).

\begin{tabular}{|c|c|c|}
\hline Protein ID & Protein name & Protein function \\
\hline Q68FP1 & Gelsolin & Cytoskelete proteins \\
\hline Q9Z1P2 & Alpha-actinin-1 & Cytoskelete proteins \\
\hline Q9QXQ0 & Alpha-actinin-4 & Cytoskelete proteins \\
\hline P85845 & Fascin & Cytoskelete proteins \\
\hline C0JPT7 & Filamin A & Cytoskelete proteins \\
\hline Q63610 & Tropomyosin alpha-3 chain & Cytoskelete proteins \\
\hline P09495 & Tropomyosin alpha-4 chain & Cytoskelete proteins \\
\hline P16086 & Spectrin alpha chain, non-erythrocytic 1 & Cytoskelete proteins \\
\hline B2GUZ5 & F-actin-capping protein subunit alpha-1 & Cytoskelete proteins \\
\hline Q5XI32 & F-actin-capping protein subunit beta & Cytoskelete proteins \\
\hline P52944 & PDZ and LIM domain protein 1 & Cytoskelete proteins \\
\hline P85970 & Actin-related protein $2 / 3$ complex subunit 2 & Cytoskelete proteins \\
\hline Q7M0E3 & Destrin & Cytoskelete proteins \\
\hline Q07266 & Drebrin & Cytoskelete proteins \\
\hline P45592 & Cofilin-1 & Cytoskelete proteins \\
\hline Q62627 & PRKC apoptosis WT1 regulator protein & Cytoskelete proteins \\
\hline Q62736 & Non-muscle caldesmon & Cytoskelete proteins \\
\hline A0A0H2UHM5 & Protein disulfide-isomerase & Enzymes \\
\hline P70583 & DUT pyrophosphatase & Enzymes \\
\hline P17751 & Triosephosphate isomerase & Enzymes \\
\hline Q63716 & Peroxiredoxin-1 & Enzymes \\
\hline P19945 & $60 \mathrm{~S}$ acidic ribosomal protein $\mathrm{PO}$ & Rybosomal proteins \\
\hline P19944 & $60 \mathrm{~S}$ acidic ribosomal protein $\mathrm{P} 1$ & Rybosomal proteins \\
\hline P02401 & $60 S$ acidic ribosomal protein $\mathrm{P} 2$ & Rybosomal proteins \\
\hline P49242 & $40 S$ ribosomal protein $\mathrm{S} 3 \mathrm{a}$ & Rybosomal proteins \\
\hline P23358 & $60 S$ ribosomal protein $\mathrm{L} 12$ & Rybosomal proteins \\
\hline
\end{tabular}




\begin{tabular}{|lll|}
\hline Protein ID & Protein name & Protein function \\
\hline P13383 & Nucleolin & Nucleic-acid binding protein \\
\hline Q66HF9 & Leucine-rich repeat flightless-interacting protein 1 & Nucleic-acid binding protein \\
\hline P13084 & Nucleophosmin & Nucleic-acid binding protein \\
\hline Q4QR85 & Methylosome protein 50 & Nucleic-acid binding protein \\
\hline B2GUV7 & Eukaryotic translation initiation factor 5B & Nucleic-acid binding protein \\
\hline P06761 & 78 kDa glucose-regulated protein & Chaperones \\
\hline P82995 & Heat shock protein HSP 90-alpha & Chaperones \\
\hline P04256 & Heterogeneous nuclear ribonucleoprotein A1 & Others protein \\
\hline B5DEL1 & BTB/POZ domain-containing protein KCTD5 & Others protein \\
\hline
\end{tabular}

Identification of several proteins in the samples: DUT pyrophosphatase, fascin and drebrin was confirmed by Western blot (data not presented).

The largest group among the identified proteins are cytoskeleton proteins. It has been proven that a number of neuropsychiatric diseases are associated with abnormal structure and atrophy of dendrites that may result from cytoskeleton disorders. Increasing evidence indicates a change in depression associated with the cytoskeleton $[18,19]$.

Chronic stress is one of the important risk factors for depression. It has been shown that during stress, an increase in glucocorticosteroid levels causes dendritic remodeling [20]. Changes in post-translational modifications of tubulin isoforms that can modulate microtubule dynamics have been observed in animal models of depression undergoing CUS (chronic unpredictable stress) [21].

\section{Actin and actin-binding proteins}

Actin's involvement in neurobiological processes associated with stress and mood disorders is probably due to the role of this protein and its regulators in neuroplasticity, in particular in excitatory synapses, as well as in anchoring postsynaptic receptors in hippocampal neurons [18].

Proteomic studies have shown that actin changes its expression levels in the hippocampus in rats after treatment with various antidepressants, which confirmed the role of microfilaments in molecular mechanisms of depression [22]. A number of binding proteins and actin regulators, including cofilin-1, have also been found to be up-regulated in various animal models of depression.

\section{Cofilin-1 and drebrin}

Cofilin-1 and drebrin are actin regulators involved in the signaling pathway mediating synaptic plasticity. Drebrin has been found to modulate glutaminergic and GABAergic activity in hippocampal neurons. A 
number of studies indicate that disturbances in the actin regulation mechanism (decrease in drebrin level and increase in dephosphorylated cofilin) result in synaptic dysfunction. In addition, drebrin level was found to negatively correlate with the severity of cognitive impairment. Gene expression analysis in rats showed that antidepressants are able to reduce the level of drebrin expression in the hippocampus [22].

\section{Filamin A}

It is believed that the pathophysiology of depression includes, among other things, the malfunctioning of the D2 dopamine receptor, as well as the reward system functions. It has been found that filamin $A$ is present in the dopamine receptor D2 and D3 and may be involved in their dysfunction [23].

\section{Caldesmon}

Almost all cytoskeleton proteins are substrates of one or more kinases. Phosphorylation by intracellular kinases may be a common feature to many actin-binding proteins. Through phosphorylation, the binding properties of actin by these proteins change, thus enabling the reconstruction of the cytoskeleton. Caldesmon phosphorylation causes its activation. The enzymes responsible for this modification are kinases belonging to MAPK, mainly ERK [24]. Although the interaction of caldesmon with MKP-1 has not been discovered so far, it is known that this protein is involved in the MAPK kinase signaling pathways. It can be postulated that increased levels of phosphatase indirectly affect caldesmon functions. This effect may be due to inhibition of ERK kinase by dephosphorylation.

Other of the identified proteins are, among others, ribosomal, chaperones, nucleic acid binding and enzymes.

It has been proven that antidepressant treatment can affect some of the chaperone proteins in the hippocampus of animals showing a depressive phenotype [25].

At present, however, it is unknown whether other identified proteins may be involved in the pathophysiology of neuropsychiatric diseases.

It is worth noting, however, that there is not much information found in the literature regarding the confirmed protein-protein interactions formed by the tested phosphatase. However, proteins have been found in the analyzed samples that have been reported in literature confirming their role in depressive disorders. The analysis of the results obtained should also take into account the fact that even if there is no direct interaction of proteins, increased MKP-1 expression may have an indirect effect on changing the protein profile in cells and inducing a depressed phenotype. So identified proteins may potentially be involved in the molecular mechanism of depression.

\section{Declarations}

Funding This work was supported by grant Miniatura 1, decision: 2017/01/X/NZ1/00975 from National Science Centre (NCN), Poland. 
Author contribution Fic contributed to the research idea, experimental design, lab work, data analysis and manuscript writing. Cieslik contributed to the lab work and data analysis. Dziedzicka-Wasylewska contributed to the research idea and manuscript writing. All the authors contributed to the final draft of the manuscript.

\section{Compliance with Ethical Standards}

Conflict of interest All authors have declared no conflict of interests in this work.

Informed consent The authors declare their consent to publish the data presented in this research.

Consent for participate All the authors have approved the manuscript that is enclosed.

Consent to publish The authors agreed to data publication and informed about the Publisher rules and terms.

Research involving human and/or animal participants The authors declare that the present research did not involve human participants and/or animals.

\section{References}

1. Puig O, Caspary F, Rigaut F, Rutz G, Bouveret B, Bragado-Nilsson E, Wilm E, Séraphin W B (2001) The Tandem Affinity Purification (TAP) Method: A General Procedure of Protein Complex Purification. Methods 24(3):218-229. https://doi:10.1006/meth.2001.1183

2. Li Y (2011) The tandem affinity purification technology: an overview. Biotechnol Lett 33(8):14871499. https://doi:10.1007/s10529-011-0592-x

3. Gloeckner CJ, Boldt K, Schumacher A, Ueffing M (2009) Tandem affinity purification of protein complexes from mammalian cells by the Strep/FLAG (SF)-TAP tag. Methods Mol Biol 564:359-572. https://doi 10.1007/978-1-60761-157-8_21.

4. Duric V, Banasr M, Licznerski P, Schmidt HD, Stockmeier CA, Simen AA, Newton SS, Duman RS (2010) A negative regulator of MAP kinase causes depressive behavior. Nat Med 16(11):1328-1332. https://doi 0 ( : : 10.1038/nm.2219

5. Barthas F, Humo M, Gilsbach R, Waltisperger E, Karatas M, Leman S, Hein L, Belzung C, Boutillier AL, Barrot M, Yalcin I (2017) Cingulate Overexpression of MKP-1 as a Key Factor for Depression. Biol Psychiatry 82(5):370-379. https:// doi 0 ( : : 10.1016/j.biopsych.2017.01.019

6. Jeffrey KL, Camps M, Rommel C, Mackay CR (2007) Targeting dual-specificity phosphatases: Manipulating MAP kinase signalling and immune responses. Nat Rev Drug Discov 6(5):391-403. https://doi 10.1038/nrd2289.

7. Vogt A, Tamewitz A, Skoko J, Sikorski RP, Giuliano KA, Lazo JS (2005) The benzo[c]phenanthridine alkaloid, sanguinarine, is a selective, cell-active inhibitor of mitogen-activated protein kinase phosphatase-1. J Biol Chem 280(19):19078-19086. https:// doi:10.1074/jbc.M501467200 
8. Chen $Y$, Wang $H$, Zhang R, Wang H, Peng Z, Sun R, Tan Q (2012) Microinjection of sanguinarine into the ventrolateral orbital cortex inhibits Mkp-1 and exerts an antidepressant-like effect in rats. Neurosci Lett 506(2):327-331. https:// doi 10.1016/j.neulet.2011.11.038.

9. Lee JE, Kwon HJ, Choi J, Han PL (2019) Stress-Induced Epigenetic Changes in Hippocampal Mkp-1 Promote Persistent Depressive Behaviors. Mol Neurobiol 56(12):8537-8556. doi:10.1007/s12035019-01689-4

10. Atrooz F, Liu H, Kochi C, Salim S (2019) Early Life Sleep Deprivation: Role of Oxido-Inflammatory Processes. Neuroscience 406:22-37. doi:10.1016/j.neuroscience.2019.02.021

11. Greene LA, Tischler AS (1976) Establishment of a noradrenergic clonal line of rat adrenal pheochromocytoma cells which respond to nerve growth factor. PNAS 73(7):2424-2428. https://doi 10.1073/pnas.73.7.2424.

12. Sasaki K, El Omri A, Kondo S, Han J, Isoda H (2013) Rosmarinus officinalis polyphenols produce antidepressant like effect through monoaminergic and cholinergic functions modulation. Behav Brain Res 238:86-94. https://doi 10.1016/j.bbr.2012.10.010.

13. Large Insertions: Two Simple Steps Using QuikChange II Site-Directed Mutagenesis Kits. Application Note. 2010, Agilent Technologies, Inc

14. Bradford MM (1976) A rapid and sensitive method for the quantitation of microgram quantities of protein utilizing the principle of protein-dye binding. Anal Biochem 72(1-20): 248-254. https://doi 10.1006/abio.1976.9999

15. Laemmli UK (1970) Cleavage of structural proteins during the assembly of the head of bacteriophage T4. Nature 227(5259):680-685. https://doi:10.1038/227680a0

16. Hughes CS, Foehr S, Garfield DA, Furlong EE, Steinmetz LM, Krijgsveld J (2014) Ultrasensitive proteome analysis using paramagnetic bead technology. Mol Syst Biol 10:757. https://doi 10.15252/msb.20145625.

17. Wiśniewski JR, Zougman A, Nagaraj N, Mann M (2009) Universal sample preparation method for proteome analysis. Nat Methods 6(5):359-362. https://doi 10.1038/nmeth.1322.

18. Piubelli C, Carboni L, Becchi S, Mathé AA, Domenici E (2011) Regulation of cytoskeleton machinery, neurogenesis and energy metabolism pathways in a rat gene-environment model of depression revealed by proteomic analysis. Neuroscience 176:349-380. https://doi 10.1016/j.neuroscience.2010.12.043.

19. Choi JE, Lee JJ, Kang W, Kim HJ, Cho JH, Han PL, Lee KJ (2018) Proteomic Analysis of Hippocampus in a Mouse Model of Depression Reveals Neuroprotective Function of Ubiquitin Cterminal Hydrolase L1 (UCH-L1) via Stress-induced Cysteine Oxidative Modifications. Mol Cell Proteomic 17(9):1803-1823. https://doi 10.1074/mcp.RA118.000835.

20. Chen Y, Dubé CM, Rice CJ, Baram TZ (2008) Rapid loss of dendritic spines after stress involves derangement of spine dynamics by corticotropin-releasing hormone. J Neurosci 28(11):2903-2911. https://doi 10.1523/JNEUROSCI.0225-08.2008. 
21. Yang C, Wang G, Wang H, Liu Z, Wang X (2009) Cytoskeletal alterations in rat hippocampus following chronic unpredictable mild stress and re-exposure to acute and chronic unpredictable mild stress. Behav Brain Res 205(2):518-524. https://doi 10.1016/j.bbr.2009.08.008.

22. Carboni L, Vighini M, Piubelli C, Castelletti L, Milli A, Domenici E (2006) Proteomic analysis of rat hippocampus and frontal cortex after chronic treatment with fluoxetine or putative novel antidepressants: CRF1 and NK1 receptor antagonists. Euro Neuropsychopharmacol 16(7):521-537. https:// doi:10.1016/j.euroneuro.2006.01.007

23. Mischoulon D, Hylek L, Yeung AS, Clain AJ, Baer L, Cusin C, lonescu DF, Alpert JE, Soskin DP, Fava M (2017) Randomized, proof-of-concept trial of low dose naltrexone for patients with breakthrough symptoms of major depressive disorder on antidepressants. J Affect Disord 208:6-14. https:// doi 10.1016/j.jad.2016.08.029.

24. Wang CL (2008) Caldesmon and the regulation of cytoskeletal functions. Adv Exp Med Biol 644:250-272. https://doi:10.1007/978-0-387-85766-4_19

\section{Figures}

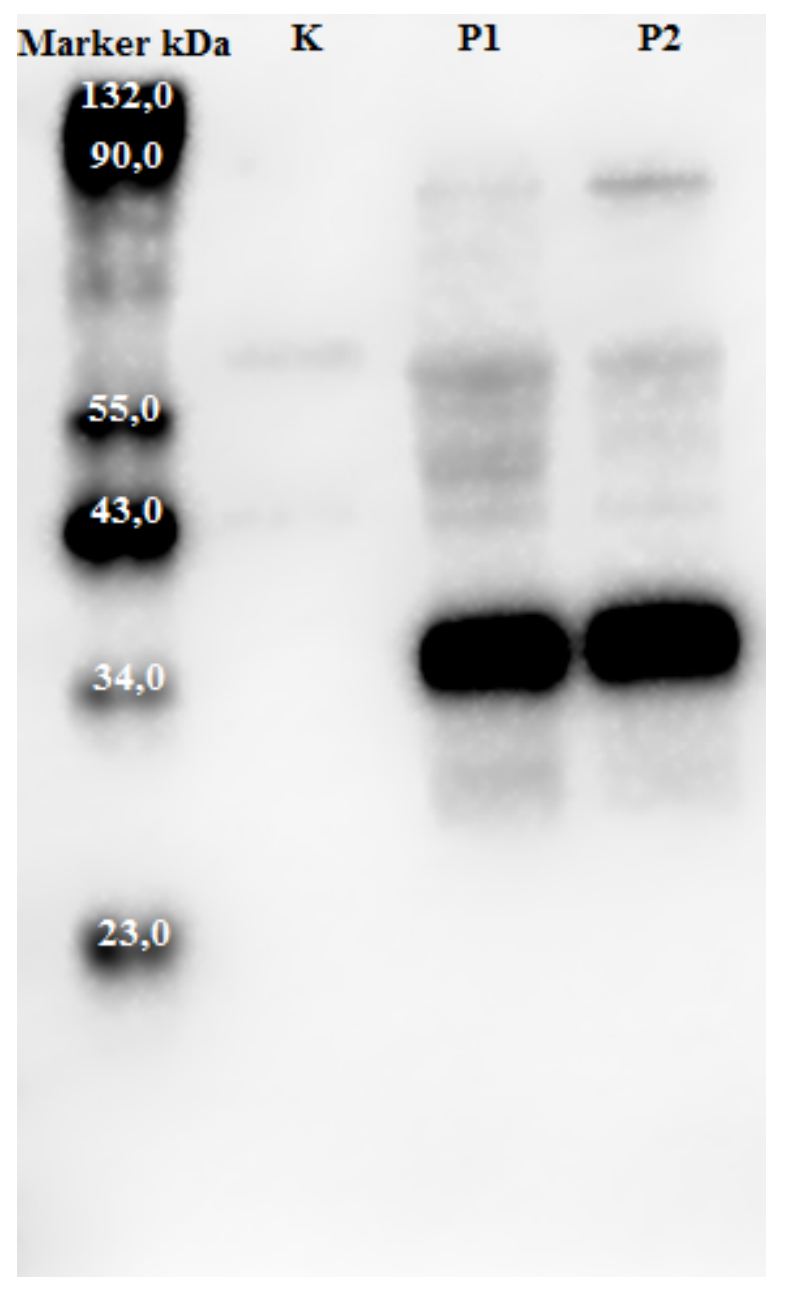

\section{Figure 1}


Western blot analysis of the cell lysates. Marker, Cruz Marker ${ }^{\text {TM }}$ Molecular Weight Standards: sc- 2035, Santa Cruz Biotechnology; K - negative control, untransfected cells; P1- first of the selected clones (transfected cells); P2 - second of the selected clones (transfected cells).
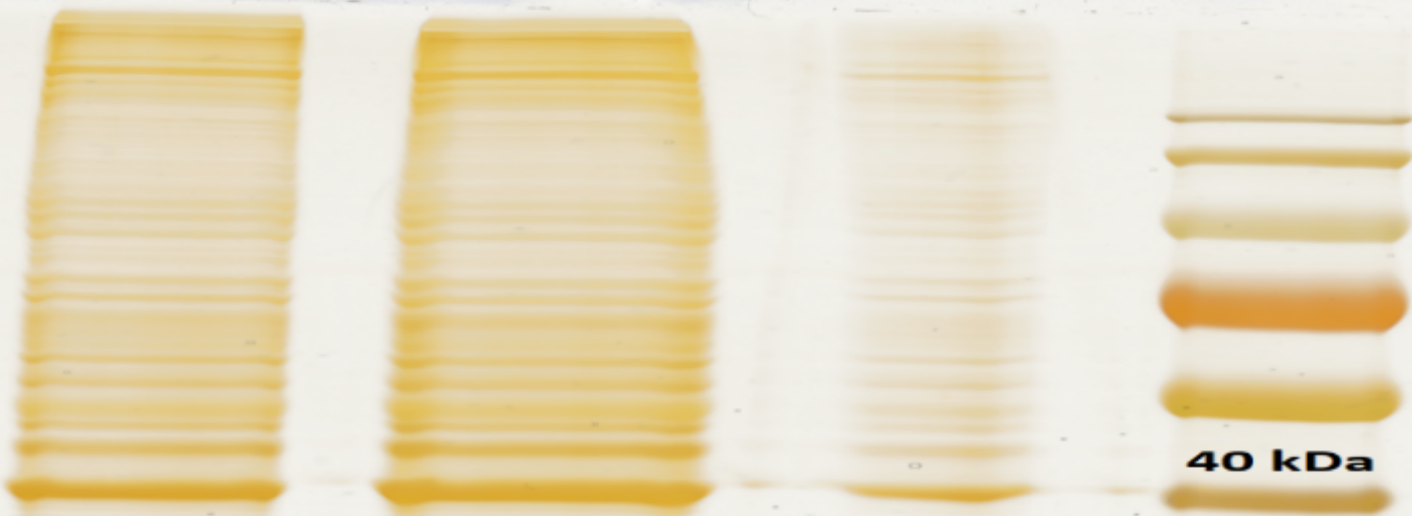

$40 \mathrm{kDa}$

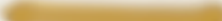

1

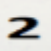

3

marker

\section{Figure 2}

$12 \%$ SDS-PAGE with silver staining after TAP procedure. Lane 1- total cell lysate, 2- clear total cell lysate (after centrifugation), 3- eluate after STREP purification, marker PageRuler Prestained Protein Ladder, 26616 (Thermo Scientific), 4 - eluate after FLAG purification. 